\title{
Accidental administration of ketamine in the gastrointestinal mucosa
}

Kollmann-Camaiora A, Tapia B, Alsina E. Gilsanz F La Paz University Hospital, Madrid, Spain

$凶$ Ketamine acts predominantly by antagonizing the $\mathrm{N}$-methyl-D-aspartate receptor, has a chiral structure and is metabolize by the cytochrome P450 (CYP) 3A and CYP2B6 enzymes.

$\otimes$ The most common administration routes are intravenous and intramuscular, although it can be administered subcutaneously and oral; but due to extensive first-pass metabolism it has a low bioavailability.

\section{CASE REPORT}

73y.o.ASAll male scheduled for colonoscopy due to mild haematochezia.

\section{Anaesthesia:}

- Sedation with spontaneous ventilation

- Standard monitoring: EKG, pulse-oxymetry, NIBP

- IV bolus of ketamine $15 \mathrm{mg}+$ propofol 50mg

- IV propofol infusion at $150 \mathrm{mg} / \mathrm{h}$

\section{Gastroenterology:}

- $12 \mathrm{~mm}$ polyp in the ascending colon

- Elevated with diluted methylene blue injected in the mucosa

- Procedure without incidents

PACU: modified Aldrete Score 10/10 20 min after procedure

\section{While performing the next procedure:} WHERE IS THE KETAMINE???

After thoroughly looking in the procedure's room we discovered that the methylene blue had been diluted in a labelled bag containing ketamine diluted in saline.

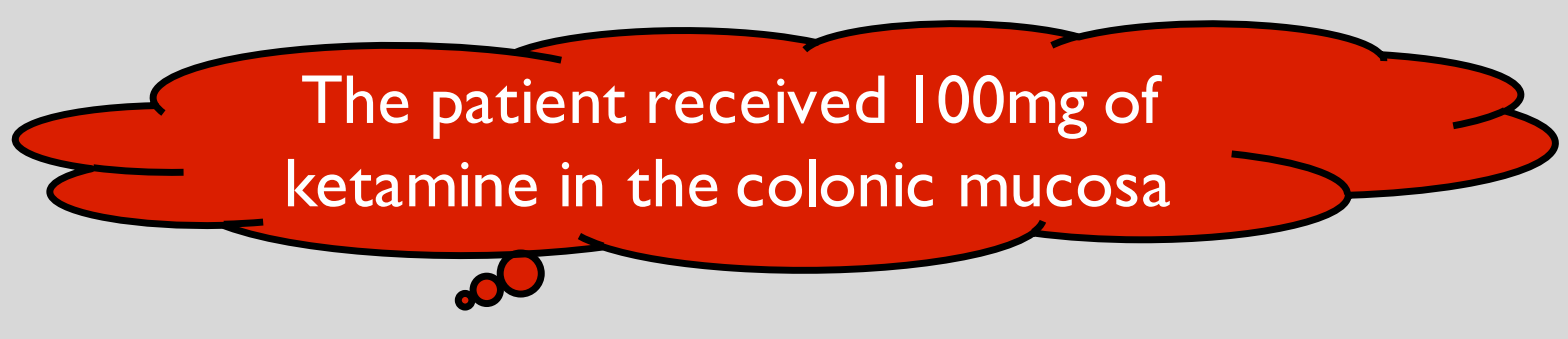

We informed the patient, he was kept under observation at the PACU for $12 \mathrm{~h}$, were he was asymptomatic and later discharged home.

\section{DISCUSSION}

$凶$ Safety is a team effort and commitment, however, even with correctly labelled medication errors can occur; and it is important to come forward to the patients about it.

$凶$ This is the first case report of ketamine administration in the gastrointestinal mucosa

$凶$ The patient didn't develop any symptoms of ketamine administration which could indicate that it was not absorbed, or at least not fully, by the gastrointestinal mucosa.

\section{LEARNING POINTS}

Ketamine appears not to be absorbed by the gastrointestinal mucosa

More studies are necessary to fully understand the pharmacokynetics and pharmacodynamics of this drug

It is vital to label all the medication, and also to re-check constantly 